\title{
Escalada urbana - faces de uma identidade cultural contemporânea
}

\begin{abstract}
RESUMO
Esse artigo propõe levantar discussões sobre os ambientes artificiais de escalada, os quais têm surgido como formas de conquista de espaços, tratando-se de uma opção de escolha por um tipo de comportamento próprio de uma camada social. Os vínculos, as relações de amizade, aí estabelecidos, são mais fortalecidos $e$ duradouros, justamente pela relação mais direta estabelecida com a prática e com os outros escaladores. $O$ grupos de escalada urbana que se formam, a cada dia, fazem parte de um movimento de resistência frente ao processo de racionalização e à desordem das cidades, manifestando inovação e criatividade, preservando e promovendo a sociabilidade, como reação ao individualismo. Os muros de escalada, espalhados pelos diversos cantos da cidade, surgem, portanto, enquanto formas de inovação e expressão cultural contemporânea, solidificados por uma política de amizade. Palavras-chave: Lazer; Ambientes artificiais de escalada; Sociabilidade urbana.
\end{abstract}

\section{ABSTRACT}

This study has investigated the relationships established in the sporting climbing in artificial atmospheres, having as startingfor the analysis the GEEWs (Group of Sporting Climbing from Unicamp) climbing wall, located at Physical Education Faculty at Campinas State University. These artificial places appear as forms of conquest spaces, being a choice option for a type of behavior from a social class. The bonds, the friendship relations are strengthened and durable, because ofthe direct relationship established with thepractice and with the other climbers. GEEU, as well as other groups ofurban climbing that are formed, every day, ispart of a resistance movement

\section{Alcyane Marinho \\ Heloisa Turini Bruhns \\ FEF/Unicamp}

to the rationalization process and to the cities disorder which manifests innovation and creativity, preserving and promoting the sociability, as a reaction to the individualism. The climbing walls, spread in the several corners of the city, appear in this perspective: innovation forms and contemporary cultural expression, solidified byfriendship politics. Key-words: Leisure; Climbing Artificial Walls; Urban Sociability.

\section{INTRODUÇÃO}

Como é possível praticar alguma atividade capaz de explorar as potencialidades do corpo, oportunizando, no mínimo, prazer, em um circuito onde os prédios e os carros são dominantes, onde as diferentes poluições provocam sérios danos à saúde, onde o barulho é ensurdecedor e o verde das árvores é quase inexistente? Será possível, em pleno centro urbano, existirem locais onde os corpos possam se encontrar, tocarem-se e envolverem-se, formando singulares focos de relações? Essas perguntas norteiam este artigo, .representando pontos de partida para refletirmos sobre o surgimento dos ambientes artificiais de escalada.

Por vários motivos, aos quais nos deteremos logo a seguir, foi criada a escalada em ambiente artificial que pode ser indoor ou não (existem muitos muros - ou paredes, como são também denominados - artificiais de escalada que não são, necessariamente, indoor. No caso do Brasil, devido ao fator climático, é bem menor a necessidade de se ter muros em locais fechados e cobertos. Não esquecendo também do fator econômico: são maiores os gastos para se construir, por exemplo, um ginásio coberto de escalada e, por contrapartida, são construídos, inclusive, muros em paredes externas das próprias residências dos interessados). $\mathrm{O}$ "desafio" é realizado em uma parede 


\begin{abstract}
(1) com várias agarras artificiais, fabricadas de areia e : resina, de textura parecida com as rochas naturais. As : agarras são fixadas à parede, formando caminhos de : diferentes níveis de dificuldade.

Esses dados permitem acreditar que os ambientes artificiais para cenários de aventura têm o potencial de se tornar uma alternativa definitivamente assumida. Atualmente, nos EUA, muitas empresas comerciais fabricam muros artificiais de escalada e equipamento Attariam, em 1987, já esclarecia que os ambientes de : escalada indoor são utilizados para a prática de : movimentos específicos aplicados, posteriormente, : nas rochas. Em outras palavras, é uma forma de : treinamento, não só para os iniciantes, mas também : para suprir a necessidade de se ter muros artificiais : para os escaladores profissionais poderem escalar em : para uso particular ou institucional em resposta à crescente popularidade desse esporte (Attariam, ibidem:28-32). Para ilustrar esse fato, Fesko, em 1992, publicou um artigo demonstrando como, ao longo da América do Norte, era estimado de mil a mil e quinhentos o número de áreas de escalada indoor disponíveis ao público.
\end{abstract} locais onde, principalmente, o inverno é rigoroso.

Além disso, os participantes podem aprender e praticar : o esporte em um ambiente controlado e seguro. Uma : outra característica, igualmente importante, desses: tipos de ambientes artificiais é a acessibilidade. : Normalmente eles têm uma localização central nas : cidades, permitindo : um rápido e fácil : Será possível, em pleno centro deslocamento aos : urbano, existirem locais onde praticantes. os corpos possam se encontrar, tocarem-se e envolverem-se, formando singulares focos de Ainda, segundo: Attariam (1989), o muro : relações? artificial de escalada: também pode ter outras : formas de

utilização, além da aprendizagem e do treinamento, tais como: educação e recreação.

Sob essa perspectiva, há um interessante estudo de : Humberstone (1995) tratando das interações entre : crianças, a partir de atividades outdoor: (especificamente a escalada) trazidas para ambientes : indoor, em aulas de Educação Física. Nesse estudo, : a autora constatou que as atividades de escalada : podem ser utilizadas para satisfazer uma variedade : de objetivos educacionais, oportunizando diferentes : níveis de desenvolvimento: coletivo (habilidades : cooperativas e de comunicação); pessoal (auto- : estima); cognitivo (tomadas de decisão; resolução de : problemas) e físico (aptidão e desenvolvimento de : habilidades motoras). Podendo, da mesma forma, : serem utilizadas como atividades recreacionais, com : fim nelas mesmas ${ }^{2}$.

No Brasil, essa atividade, também, vem aumentando de forma crescente. Não é raro nos depararmos com o interesse de reportagens em anunciar a escalada em ambientes artificiais enquanto uma oportunidade para se aventurar. Uma publicação do SESC - São Paulo ${ }^{3}$ apontou a enorme adesão às atividades esportivas na natureza citando, para tal, o ciclismo, o pára-quedismo, o bóia-cross, o rafting e o alpinismo 4 . Este, que de acordo com a reportagem, é considerado um dos esportes mais perigosos do mundo,"... vem ganhando adeptos ecléticos e nem tão malucos. As academias indoor proliferam no país, trazendo as dificuldades de uma escalada em rocha para um ambiente seguro e divertido: dentro da cidade, ao lado da casa do novo atleta".

Mesmo a reportagem sendo específica de esportes de aventura na natureza, no caso da escalada, a ênfase não foi dada à atividade outdoor, nas rochas, mas sim à escalada em ambientes artificiais, demonstrando, com isso, o interesse pelo tema.

Uma questão pode ser evidenciada: as pessoas têm encarado como comum a escalada em muros artificiais; entretanto, o trazer as dificuldades da natureza para a cidade, muitas vezes, tem sido tratado meramente como uma conseqüência, um fácil acesso e uma comodidade com maior segurança. É necessário, por isso, destacar as outras conotações que os ambientes artificializados recebem não só pelos praticantes mas, também, por aqueles que procuram entender esse movimento.

Pode estar ocorrendo o que Maffesoli (1996) 
denominou de "naturalização da cultura" ${ }^{5}$ ? Cremos : que a tentativa de tornar a prática da escalada realizada : em ambientes artificiais a mais parecida possível com : a prática executada em rochas possa ser um exemplo : desse processo. A passagem da atividade realizada em " ambientes naturais para os artificiais será explorada : aqui, partindo da idéia do "gosto pelo natural" : (Maffesoli, ibidem:246) manifestado em nossa : contemporaneidade ${ }^{6}$. Essa tendência é percebida por : meio da tentativa de trazer a natureza para os padrões : urbanos, de forma bem ilustrada pela construção do : muro do GEEU (Grupo de Escalada Esportiva da : Unicamp). Mais que uma "naturalização da cultura" : parece estar havendo um certo tipo de: "desterritorialização" da atividade, bem como de seus : praticantes.

Essa mobilidade é notada em inúmeras situações da : vida e, como já destacou Milton Santos (1997), não : são só os homens quem mudam de lugar (como : turistas, migrantes ou trabalhadores), mas também : os produtos, as mercadorias e as imagens, surgindo, : assim, a idéia de desterritorialização.

Antes de prosseguir nessa discussão, cabe destacar : algumas das várias distinções entre o muro de escalada : da Unicamp e outros muros e ginásios de escalada : esportiva existentes na região de São Paulo. De : antemão, ressaltamos que a construção de todos esses : locais, especializados em escalada esportiva, é um dos : fatores que contribui para a conquista de espaço, : divulgação e fortalecimento dessa prática junto ao * meio esportivo.

A começar pelo espaço, o muro do GEEU foi adaptado : a um local já existente, sendo montado na parte externa : da parede da Biblioteca da Faculdade de Educação : Física tratando-se, exatamente, de uma área de oito : metros de altura por dez metros de largura. Os próprios : membros do GEEU capacitaram esse espaço para a : prática da escalada. Toda a estrutura foi montada e : colocada manualmente, permitindo dizer que o muro : do GEEU constitui-se em uma construção, : praticamente, artesanal. No muro estão montadas três : diferentes vias verticais (variando o grau de dificuldade : conforme o interesse dos escaladores) e uma via : negativa com um pequeno teto.
Apesar da disponibilidade dessa área, o GEEU não conta com nenhum outro tipo de apoio, quer seja da Faculdade de Educação Física ou da própria Unicamp; portanto, o GEEU, sendo uma entidade sem fins lucrativos, mantém em funcionamento o muro de escalada por meio de recursos próprios adquiridos mediante o pagamento de uma semestralidade pelos membros do grupo. Todo o dinheiro arrecadado é revertido em favor dos membros, sendo utilizado, principalmente, para a reposição do material de escalada.

Nesse momento, é importante mencionar um fato: quando perguntamos aos escaladores do GEEU porque eles construíram o muro ali, na FEF (Faculdade de Educação Física), eles responderam que não havia nenhum motivo especial e poderia ter sido escolhido qualquer outro lugar. Uma ilusão que talvez os tenha motivado a essa escolha foi o fato de acreditarem que ali seria um local no qual eles, possivelmente, poderiam conseguir maior apoio, haja vista ser uma faculdade dispondo de diversos projetos esportivos.

Diante dessa situação, referimo-nos a Ortega (2000) para apontar a existência de múltiplas possibilidades de ação, em vários espaços públicos, com a possibilidade de serem constantemente criados e redefinidos, sem precisar unicamente de suporte institucional. Todas as vezes que os indivíduos se ligarem por meio do discurso e da ação, o agir significará começar, experimentar, criar algo novo. $\mathrm{O}$ espaço público como espaço entre os seres humanos pode, portanto, surgir em qualquer lugar, não existindo um locus privilegiado.

Ortega (op. cit:: p.23-24), baseia-se em Hannah Arendt, Foucault e Derrida, para propor uma recuperação do espaço público - "a política compreendida como atividade de criação e de experimentação"." Dessa forma, a amizade, conforme o autor, representaria um "exercício do político, um apelo a experimentar formas de sociabilidade e comunidade, a procurar alternativas às formas tradicionais de relacionamento". O muro do contemporâneo GEEU, fortalecido por laços de amizade, parece ser um exemplo desse tipo de local onde novas formas de experimentações estão ocorrendo. 


\section{ESCALANDO EM OUTROS MUROS}

Todas essas características diferem-se das encontradas em entidades particulares de escalada, as quais foram especificamente construídas para a prática da atividade, visando, prioritariamente, o lucro. Podem ser destacados três grandes locais especializados em escalada esportiva no Brasil: "90 Graus", o primeiro ginásio a ser construído; "Ginásio Casa de Pedra" e, o mais recente, "Vertical Indoor"; todos eles estão localizados em São Paulo.

Detalharemos algumas características desses locais especializados em escalada, procurando apontar alguns dos vários aspectos em comum entre os mesmos, tais como: as atividades oferecidas, os equipamentos utilizados, o tamanho e as características de suas instalações.

90 Graus, idealizado por Paulo Gil, foi o primeiro ginásio de escalada esportiva urbana a ser construído no Brasil, em 1993, cujo objetivo, de acordo com os coordenadores, é formar escaladores e contribuir para o desenvolvimento do esporte no Brasil.

O Ginásio de Escalada Casa de Pedra foi idealizado "na tentativa de trazer ao público brasileiro a oportunidade de usufruir um novo conceito de escalada esportiva", no qual, segundo os organizadores, a diversão está aliada à seriedade e à segurança tornando o esporte acessível a todos aqueles que buscam por uma atividade saudável e diferente.

Não fugindo desses objetivos, Vertical Indoor é o mais recente ginásio de escalada esportiva construído em São Paulo.

Todos esses três locais possuem instalações cobertas, com áreas construídas de $410 \mathrm{~m}^{2}, 900 \mathrm{~m}^{2}$ e $500 \mathrm{~m}^{2}$, respectivamente, disponibilizando distintas vias de escaladas com vários níveis de dificuldades. Estas podem ser: Tope Rope (as cordas vindo de cima, proporcionam segurança e simplicidade na iniciação à atividade); Área de guiar (o escalador passa sua corda de segurança pelos mosquetões à medida que evolui em sua escalada, exigindo maior técnica e experiência, proporcionando maior desafio ao escalador); Área de Boulder (refere-se a paredes baixas, nas quais o escalador progride lateralmente, havendo maior possibilidade de serem criadas diferentes movimentações) e, ainda, paredes específicas para crianças.

As agarras que compõem as vias são coloridas; cada via possui uma cor muito viva e diferente. Algumas vias se cruzam, fazendo com que as cores "dancem" pelas paredes. O colorido das agarras, aliado ao colorido das roupas e dos equipamentos dos escaladores, iluminam o local de uma certa aura de alegria. Esta, por sua vez, mistura-se às faces joviais e concentradas dos praticantes.

Há uma multiplicidade de opções, nesses locais, oportunizando diferentes formas de práticas e, dependendo do gosto, simultaneamente a alguma música, programa de televisão ou filmes em vídeos (apresentados em telão).

Nesses ginásios são oferecidos, aos freqüentadores, equipamentos homologados por entidades internacionais (inclusive os infantis), garantindo, segundo eles, total segurança aos praticantes. Eles também possuem espaços voltados à recepção do público; áreas de alongamento e aquecimento e vestiários (banheiros com duchas e armários), oportunizando conforto e diversidade aos interessados.

As equipes responsáveis pela coordenação, manutenção e administração desses espaços é composta, em sua maioria, por escaladores que já vivenciaram ou vivenciam a escalada.

Esses locais especializados em escalada esportiva funcionam durante o ano inteiro, ao longo da semana e, também, aos fins de semana, com horários bastante flexíveis, alternando entre manhã, tarde e noite. Há inúmeras formas de pagamento: diárias (os preços nos ginásios variam de $\mathrm{R} \$ 10,00$ a $\mathrm{R} \$ 20,00)$, mensalidades ou trimestralidades.

Refletindo sobre esses valores e outras taxas adicionais, é possível afirmar que a escalada, nesses tipos de - ginásios é, de certo modo, elitista, voltando-se para : uma clientela selecionada, pois não é qualquer pessoa 
que possui condições financeiras suficientes para praticar a atividade oferecida, mesmo sabendo da gama de alternativas disponíveis na estrutura do local. Esse fato contribui, sobremaneira, para o aumento do número de muros construídos, artesanalmente, ao longo dos últimos anos, em faculdades, escolas, casas etc.

Tanto o Ginásio Casa de Pedra quanto o 90 Graus e o Vertical Indoor dispõem de algumas atividades em comum (cujos valores não estão incluídos nas diárias):

- Curso básico de Escalada Esportiva Indoor - Curso de Escalada em Rocha

- Acompanhamento individual de escalada esportiva. Segundo um dos instrutores da Casa de Pedra, "esse acompanhamento funciona como um 'personal trainner', onde o instrutor faz um acompanhamento individual com seu aluno, corrigindo-o e ajudandoo da forma que for necessário".

- Curso de Técnicas Verticais (para diferentes níveis).

- Convênios com agências de ecoturismo e esportes de aventura.

- Festas infantis. O ginásio é alugado para festas de aniversário, incluindo monitores, equipamentos e atividades. Existem normas e detalhes a serem aceitos para a contratação do espaço. A principal atividade para as crianças é a escalada, entretanto, há diferentes atividades disponíveis conforme o interesse e a idade das crianças, tais como: balanço com cordas; cabo de guerra; tirolesa (passagem por corda suspensa). - Programa de Participação Empresarial. Sob o lema: "Fuja da rotina e melhore sua qualidade de vida!", a Casa de Pedra fornece serviços voltados a empresas, podendo ser montados diferentes tipos de projetos incluindo: palestras, jogos, desafios, etc. Também são promovidas saídas ao ar livre com atividades como: rapei, escalada, caminhada, rafting, canyoning, etc. Algumas idéias sobre esses programas podem ser observadas por Alexandre, diretor Presidente da Casa de Pedra:

"Amplamente utilizado na Europa e Estados Unidos, trouxemos ao Brasil uma nova ferramenta para formação do profissional moderno. Utilizando o Alpinismo de forma totalmente inovadora, montamos programas para empresas baseados nas virtudes e rotina do Alpinista, trabalhando com analogias e exemplos, aliados a muita diversão e prazer. Com uma malha grande de possibilidades e um conceito didático totalmente diferente, nós faremos seus profissionais compreenderem e aprimorarem técnicas para o alcance dos seus objetivos com sucesso".

Várias críticas têm sido elaboradas a esse respeito, nas quais se incluem propostas referentes à reengenharia, questionando o enfoque mecânico subjacente nessa proposta, pois é difícil afirmar que um profissional, enfrentando desafios em um ambiente incerto e inseguro, automaticamente, será capaz de enfrentar os desafios da empresa, bem como do mercado financeiro. Questiona-se, da mesma forma, a promessa de mudanças bruscas de comportamento. Se um empresário tiver características de personalidade que o classifiquem como uma pessoa tímida, não serão as atividades de aventura que o tornarão, mecanicamente, um profissional extrovertido diante do ambiente de trabalho e das necessidades de flexibilidade desinibição para tratar É possível afirmar que a os problemas escalada, nesses tipos de empresariais. ginásios é, de certo modo, elitista, voltando-se para uma

Mesmo com todas essas clientela selecionada, pois não críticas, cada vez mais, as instituições especializadas (como academia acima é qualquer pessoa que possui condições financeiras suficientes para praticar a citada e outras empresas atividade oferecida. de aventura) têm vendido propostas desse tipo para grupos de empresários e obtido, como retorno, mais adesão às atividades. Com o título: "Os impossíveis - super-heróis de final de semana viciam-se em adrenalina e carregam a empolgação para o seu dia-a-dia", uma reportagem da Revista da Folha (1999:9) ilustra esse fato. Foi possível detectar na fala de um empresário, que participou, em um único final de semana, de inúmeras atividades de aventura (bóia-cross, rafting, cascading, entre outras), a certeza de ter conseguido assimilar as "lições" inseridas no interdito da aventura (segundo a proposta vendida), tais como: desenvolvimento de liderança, resistência a pressões e maior capacidade de trabalho individual e em equipe. $\mathrm{O}$ empresário em questão, "contabilizando" os efeitos daquele final de 
semana, além de comentar sobre seu bom estado de humor no trabalho e senso de coletividade, também mencionou a superação de dificuldades:

"Consegui finalizar um trabalho complicado em poucas horas. Normalmente, eu levaria dias para fazer a mesma tarefa, no entanto foi fluindo tão fácil que, quando percebi, já tinha acabado".

Apesar dessa afirmação, tomando as críticas realizadas acima sobre a ingenuidade dessas propostas, nada garante que uma semana produtiva de trabalho subseqüente às atividades, anteriormente comentadas, seja resultado dessas vivências.

Ainda sobre os ginásios de escalada, se os freqüentadores não possuírem os equipamentos necessários, esses locais dispõem dos mesmos para serem alugados. Nesses locais, podem, ainda, ser encontradas: lanchonetes, lojas de equipamentos e roupas e, até mesmo, áreas específicas de convivência (sala de estar).

Além de todas essas oportunidades acima descritas, existem os muros móveis de escalada que têm sido construídos por diversas empresas de aventura, as quais descobriram neles, uma opção lucrativa por meio da realização de eventos em locais sem estrutura para a prática da escalada, tais como ruas, shoppings, parques, acampamentos e hotéis, nem sempre próximos de academias especializadas, atraindo e entretendo crianças, hóspedes e os mais diferentes interessados. Esses tipos de muros, de fáceis manuseio e transporte, são encarados também como uma forma de divulgação, pois, neles, sempre há faixas coloridas anunciando o nome da empresa a qual pertencem, além de propagandas dos patrocinadores.

A tecnologia, nesse caso voltada ao segmento esportivo, além de possibilitar a construção de um muro de escalada, possibilitou a existência de um muro móvel, demonstrando sua capacidade de acompanhar os interesses e as necessidades da sociedade, de acordo com sua cultura e conforme o momento histórico. Esses muros artificiais relacionamse diretamente com o momento presente no qual vivemos, pois denotam características extremamente contemporâneas, tais como: facilidade de deslocamento e jogo de imagens e ações diante de uma inovada e instigante prática repleta de significado.

Featherstone (1997) aponta algumas características presentes nas experiências contemporâneas, as quais permitem situar melhor a existência dos muros móveis de escalada. E comum encontrar, nas atuais experimentações, referências à mescla desorientada de signos e imagens, ecletismo estilístico, jogos com signos, mistura de códigos, ausência de profundidade, pastiche, simulação, hiper-realidade, imediatez, experiências de intenso afeto, queda da fronteira entre a arte e a vida cotidiana, ênfase nas imagens em detrimento às palavras, entre várias outras. Conforme o referido autor, tais experiências ocorrem principalmente no contexto do lazer da cultura de consumo, estando (ou não) circunscritas a lugares e práticas específicas.

Os muros integram-se nesse contexto, representando algo novo, desterritorializado, permeados por certa mobilidade, não sendo característicos de um lugar determinado. Eles funcionam como parte de um espetáculo, ou seja, como componente de uma relação social entre pessoas, mediada por imagens e equipamentos. Não caracterizam somente um suplemento ou uma decoração da vida humana, simbolizam uma época e toda uma geração.

Várias instituições estão investindo na aquisição desses equipamentos, assim como a Vertical Indoor, a qual possui uma parede móvel, nessa perspectiva, para vários tipos eventos.

Diferentes em vários aspectos, com uma estrutura bastante inferior e semelhantes ao muro do GEEU há, também, inúmeros outros muros espalhados por todo o país - dentro de academias de ginástica, faculdades, escolas, casas e, até mesmo, bares. São estruturas mais simples porém, igualmente, - representativas, pois fazem parte das ressonâncias de um movimento mais amplo de escaladores.

Esses muros menos sofisticados surgem como reação às estruturas, consideradas por alguns, elitistas, como - formas de conquista de espaços e, além disso, 
demonstram uma opção de escolha por um tipo de : comportamento (roupas, gostos) próprio de uma : camada social. Eles despontam manifestando seus : estilos e linguagens próprios. Portanto, pode-se dizer : que a escalada não é exclusiva de determinada classe : sócio-econômica, embora tenha acessos desiguais : relacionados às condições de vida de seus praticantes.

Nesses locais mais "domésticos" pode-se perceber : um envolvimento maior entre as pessoas. Os vínculos, : as relações de amizade são mais fortalecidos e : duradouros, justamente pela relação mais direta : estabelecida com a prática e com os outros escaladores. " Enquanto os locais mais sofisticados de escalada : denotam mais "passagem" e "experimentação", estes : denotam mais "encontro" e "participação".

Procurando não generalizar por meio dos casos, mas : generalizando dentro deles (como propõe Geertz, : 1989), podemos afirmar, referindo-nos ao GEEU, a * marcante existência de uma sociabilidade urbana no : ambiente artificial de escalada. Os membros do grupo : se organizam, tentando conciliar estudos, escaladas : e todas as atividades diárias, mantendo relações afetivas " e dando sentido ao muro - lugar comum entre eles. : Isso os diferencia e os torna singulares.

São vários os pontos positivos relacionados aos muros : artificiais. Para Rodrigo Santos Magalhães, membro : do GEEU e um dos atuais coordenadores, um dos : muitos aspectos positivos da escalada em ambientes : artificiais é a repercussão que eles causam, devido ao : seu alto grau de segurança, contribuindo para que : seja retirado o rótulo de esporte mortal e elitista que : a mídia sensacionalista, muitas vezes, apregoa à : escalada de uma maneira muito genérica.

É preciso, antes de mais nada, contextualizar de qual : escalada se trata, pois, segundo muitos escaladores : do GEEU, "é uma situação ridícula serem chamados : de irresponsáveis e malucos por causa de atos pouco : inteligentes de pessoas sem conhecimento que se: arriscam a escalar, independentemente do local".

Sobre o rótulo de prática elitista, foi possível notar o : tom de desabafo de Rodrigo:
"Muitas vezes as pessoas não conhecem ou têm uma pré-concepção sobre a escalada, não têm equipamentos e acham que é muito caro, preferindo ir jogar futebol".

Essa questão de ser ou não uma prática elitista incomoda um pouco os escaladores do GEEU, os quais não querem levar esse estigma. Eles defendem a acessibilidade da prática por qualquer um, citando o próprio muro da Unicamp como um local bom, barato e acessível. Defendem, ainda, que na escalada esportiva, a necessidade de se ter muitos equipamentos é menor quando comparada com outros tipos de escalada (como no caso da escalada alpina), sem contar que esses equipamentos específicos têm uma enorme durabilidade. E, por fim, sem mencionar a facilidade em se construir pequenos muros, em casa mesmo, com alguns pedaços de madeiras e pedras.

\section{BUSCANDO A COMPREENSÃO NO "FUNDO DAS APARÊNCIAS"}

Os ambientes artificiais de escalada, sejam eles superestruturados (construídos por empresas especializadas, como no caso dos ginásios anteriormente apresentados) ou mais simples (feitos manualmente, em paredes, pelos próprios interessados) apesar de possuírem diferenças, têm em comum a oportunidade oferecida: uma atividade que, tendo uma estética e comportamento próprios, torna-os importantes espaços urbanos para o encontro de pessoas (com os mais variados fins), permitindo a fruição dos corpos.

Os seres humanos experimentam (e se adequam a) diferentes possibilidades de vivência de sensações, também, nesses tipos de estruturas esportivas. Com isso, é possível acreditar que a escolha pela prática da escalada urbana, em ambientes artificiais, pode ser traduzida por um desejo de reconciliação com a cidade e suas características urbanas, do mesmo modo que a escolha pela prática da escalada, na natureza, pode ser interpretada pela vontade de reconciliação com o meio natural. Ou, ainda, unindo os dois, o desejo e o gosto de trazer um pouco da natureza para a cidade, buscando sensibilidades originárias no montanhismo, prática que encarna as montanhas. Dessa forma, é possível concordar com Magnani 
(1999:3-4) que, mesmo diante da deterioração de espaços e equipamentos públicos, com a conseqüente privatização da esfera coletiva, com a evitação dos contatos face-a-face e o confinamento em ambientes restritos - em níveis mundiais - é possível, também, perceber "exemplos de boas práticas urbanas", atestando "um movimento ou, ao menos, focos de resistência no sentido contrário à tendência da desordem urbana" ${ }^{\prime 7}$.

Portanto, os grupos de escalada urbana (assim como outras atividades de aventura) que se formam a cada dia fazem parte desses movimentos, manifestando inovação, criatividade e espírito coletivo.

Para retomar as características físicas dos ambientes de escalada e dar prosseguimento à : Na escalada esportiva compreensão do que foi, realizada nas rochas, na anteriormente, natureza, apesar de certo $\mathrm{d}$ e $\mathrm{n}$ o $\mathrm{m}$ i n a d o : controle possibilitado pelo "naturalização da controle, possibilitado pelo cultura", utilizamos " equipamento, não se pode, Parlebas

previamente, deduzir refletindo

seqüencias motoras, muito categorias de um : menos controlar, totalmente, espaço ludo-esportivo, :

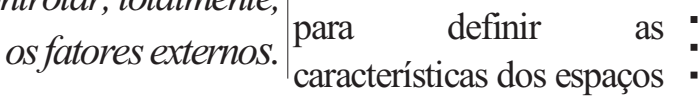
onde se realiza um jogo, tais como: dimensões e : normas, natureza e consistência (materiais), levantando algumas considerações importantes.

O autor situa duas dimensões: "domesticado" e "selvagem", em pólos contrários; entre esses dois limites se estende uma zona "semidomesticada" cujo nível de domesticação é variável e difícil de medir.

Ao pólo selvagem corresponde um meio não condicionado, incerto e instável, no qual se requer, constantemente, tomadas de informação e decisão motoras dotadas dos riscos da improvisação. O espaço oculta o imprevisto. Parlebas afirma ser esse espaço a própria natureza, na qual se desenvolvem excursões e expedições vividas pelos praticantes como uma aventura extraordinária. Tratando dessas situações nas quais o meio é instável e incerto, o autor dá exemplos da espeleologia, do vôo livre, do surfe e do próprio alpinismo, afirmando que, nessas atividades, o praticante precisa estar sempre avaliando a distância, a velocidade, tentando perceber os possíveis obstáculos. Nessas situações são requisitados todos os sentidos, de forma mais intensa.

Na escalada esportiva realizada nas rochas, na natureza, apesar de certo controle, possibilitado pelo equipamento, não se pode, previamente, deduzir seqüências motoras, muito menos controlar, totalmente, os fatores externos. Agnes Margarethe Moinar, membro do GEEU, permitiu-nos constatar esses dados:

"...na rocha eu acho que você treina muito mais sua atenção porque você tem vias mais longas... tem momentos na via que você não enxerga a pessoa que tá escalando; então, eu tô dando segurança e eu não enxergo, eu tenho que tá prestando muita atenção. Isso é uma coisa que é bom na escalada, porque você tem que realmente ficar prestando a atenção naquilo que você tá fazendo, não dá pra ficar pensando em outra coisa. Porque o cara tá lá, você não tá vendo ele, às vezes você nem ouve ele porque se venta ao contrário, ele vai falar e você não vai ouvir. Então, você tem que estar bem ligado na tensão da corda, se ele tá indo, se ele não tá indo; isso é gostoso na rocha pra você mesmo prestar atenção e aprimorar essas coisas..."

Por outro lado, o pólo domesticado corresponde ao meio estável e previsível. Nesse espaço mais controlado, é possível programar as seqüências de comportamento em formas de estereótipos motores eficazes. Os aspectos de informação e decisão da conduta motora, em resposta a esse meio "imutável", reduzem-se a sua expressão mais simples. Atletismo e halterofilismo são alguns exemplos colocados por Parlebas. Estendemos seus exemplos à escalada praticada pelo GEEU, no muro artificial, mantendo relação estreita com o pólo domesticado. Agnes aponta alguns aspectos referentes ao controle e ao domínio:

"...No muro é mais fácil porque você tá sempre enxergando a pessoa, se por exemplo, ela tá naquela passagem que você acha que vai cair ou não, entendeu? Mas você já tá preparada pra fazer ${ }^{1} \mathrm{a}$ 
segurança dela... Por exemplo, em indoor você tem ' as agarras certas pra pisar e pegar, na rocha não, você : descobre, você tem que ter também aquele... 'feeling' . de você tá percebendo 'ah, aqui eu posso pisar'. " Desse tamaninho, mas você pode pisar, pode escolher, " pode variar movimentos, entendeu?..."

Esses distintos ambientes de escalada possuem elementos, os quais se mesclam e, mesmo mantendo : suas particularidades, contrapõem-se. No muro : artificial, o espaço é delimitado, esquematizado e : assegurado (em contraposição à imprevisibilidade : presente na prática da escalada junto à natureza) com : um significado próprio e singular. Talvez esteja aí um : dos motivos que atraiam tantos interessados, muitas : vezes não-esportistas, para as estruturas artificiais.

Os muros de escalada surgem na tentativa de eliminar " os riscos e os perigos existentes nessa prática, entretanto, ao eliminá-los, não eliminam o sentido de : aventura intrínseco na atividade. Diferente disso, : apenas o modificam. A aventura passa a ter relação : direta com o novo significado dado à prática.

Para prosseguir na discussão do interesse e da busca : pelo artificial, reportamo-nos a Harvey (1992) para : tratar da questão das imagens em nossa contemporaneidade. O autor ressalta, diante dos : processos de produção e reprodução de imagens, a : importância do "simulacro" diante da ausência da : própria imagem. Harvey (ibidem:261) designa : simulacro como sendo "um estado de réplica tão : próxima da perfeição que a diferença entre o original : e a cópia é quase impossivel de ser percebida".

A produção de imagens como simulacros, nos mais " diversos domínios (políticos, individuais, etc.) torna- : se possível a partir das inovadas tecnologias, as quais : oportunizam a reprodução de forma tão exata e : perfeita, chegando a colocar em dúvida a diferença : entre a réplica e o original.

Essa discussão enquadra-se, atualmente, no que diz : respeito à construção de ambientes artificiais de : escalada (mas não só; estendendo-se a ambientes artificiais de surfe, de snowboarding, de esqui, etc. ${ }^{8}$ ), " os quais são construídos visando a maior semelhança possível com rochas naturais.

Por se assemelharem notamente às rochas, muitas paredes artificiais de escalada podem ser, portanto, consideradas simulacros; dando forma à própria ausência de rochas. Nos Estados Unidos e Europa existem verdadeiras esculturas em formato de rocha artificial, dentro de academias e ginásios, e seus moldes têm sido, crescentemente, trazidos para o Brasil.

Sejam os locais de escalada simulacros perfeitos ou não, neles, inusitadamente despontam tentativas de dar um novo significado à cidade por meio de suas marcantes características.

Reportamo-nos a Magnani, ao utilizar Otília Arantes, discutindo a questão do "lugar" no cenário contemporâneo. Em seus ensaios, Arantes analisa algumas obras, tendências e teorias relacionadas à arquitetura - campo de estreita relação com a cidade. Em nossa cultura, fortemente caracterizada pela mídia, a autora explora a inter-relação entre "civilização midiática" e a arquitetura da contemporaneidade, mostrando que, "se vivemos sob o signo do olhar, sob o império da imagem e no âmago de uma civilização do simulacro, o palco dessa irrealidade é a metrópole moderna". Contudo, em contraposição ao formalismo extremo da arquitetura pós-moderna, registra-se uma resistência: a "arquitetura do lugar" - tentativa de ressemantizar a cidade por meio da produção de espaços cheios de sentidos, buscando reanimar o espírito do lugar (Arantes apud Magnani, op. cit.: 17).

Aliada ao simulacro, a interferência do meio ambiente ${ }^{9}$ nas opções sociais é um outro fator que pode ser observado. Concordo com Tuan (1983) que o meio ambiente construído contribui para a definição das funções e das relações humanas. O fato de o GEEU ter se mobilizado, ter construído e estar convivendo no muro exemplifica essa afirmação. Os escaladores do GEEU, muitas vezes, reconhecem-se e confiam um no outro com mais facilidade e sabem como devem agir quando estão no ambiente planejado por eles e isso é observado na fala de Silvia Maria Martins de Jesus (membro do GEEU) referindo-se ao muro: 
"... a altura é limitada, é a gente que faz, nós é que : somos responsáveis pelo que estamos fazendo; somos nós que colocamos as agarras, é diferente. Eu acho: que é diferente quando você coloca uma agarra, que : você sabe que precisa tá segura, você vai preparar a : segurança, você sabe que precisa tá segura, porque : você está fazendo uma coisa pra você. Eu tô fazendo : pra que eu não caia, entendeu? É uma coisa que a : gente fez, então a gente confia mais na segurança, : talvez, porque eu fiz porque de repente eu passei : aquela corda; porque quem montou aquela parada lá em cima foi alguém que eu conheço, então eu : confio. E a pedra como é que eu posso dizer é : ilimitada, podem vir surpresas... Por isso eu diria que : o perigo talvez em uma pedra é maior. No muro eu " não diria fictício, mas eu diria que a segurança: depende da gente e quando a gente faz a gente tem : certeza, né! A gente tenta simular, é claro, chegar o mais próximo possível da adrenalina que dá escalar : uma pedra alta, mas a gente toma toda :

Não se pode, portanto, negaro que nada de pior aconteça
possibilidade da manifestação Agora os meninos estão " do lúdico, do prazer (ainda montando o negativo; nossa! A : que atrelado ao dever) e da firme, é o tempo todo: sensibilidade na vivência de conferindo, testando; : atividades em ambientes parafuso nunca é demais".

artificializados, particularmente em muros Segundo Tuan, os: artificiais de escalada. $\begin{aligned} & \text { nesse contexto do } \\ & \text { cono variar }\end{aligned}$ ambiente construído, serão as disponibilidades, no : tempo e no lugar, obrigando-os a pensar, adaptar e : inovar. Isso ocorre no muro do GEEU, haja vista a : construção do novo negativo, após meses de : planejamentos, adaptações e idealizações. Tuan : (ibidem:99) ainda ressalta que "a visão do mundo: é uma tentativa mais ou menos sistemática das: pessoas de compreender o meio ambiente".

Tendo a oportunidade de acompanhar o processo de : construção do negativo, pudemos perceber algumas : dificuldades que o permearam, tais como: horários : incompatíveis entre os membros, discordância de : idéias, alguns desentendimentos e falta de dinheiro. : Por esses motivos, podemos afirmar que somente no : momento exato em que os escaladores visualizaram " melhor o denominador comum em suas diferentes perspectivas e conseguiram, a partir daí, atingir a harmonia ideal necessária para o desenrolar da construção desse novo negativo, ela se concretizou.

Prosseguindo na discussão do espaço, é necessário introduzir os objetos e os lugares que o definem, tendo em vista o fato de as relações entre espaço e lugar serem bastante estreitas. O significado de um pode vir a se confundir com o outro. A idéia de espaço é mais abstrata e implica em liberdade; já o lugar, constitui-se em segurança. O espaço transforma-se em lugar à medida que vai adquirindo significado $\mathrm{e}$ definição, à medida que o conhecemos melhor e lhe damos valor. Ao pensar em espaço como movimento, o lugar se torna pausa. Cada pausa no movimento possibilita a uma localidade se tornar um centro de reconhecido valor (Tuan, ibidem-3-6).

O espaço testemunha a realização da história, sendo a um só tempo, passado, presente e futuro... sempre, em cada momento, uma variedade de lugares; e é no lugar (cotidiano compartilhado entre as pessoas) que a cooperação e o conflito formam a base da vida em comum. Nas palavras de Milton Santos (1997:258), lugar é um "teatro insubstituível das paixões humanas, responsáveis, por meio da ação comunicativa, pelas mais diversas manifestações da espontaneidade e da criatividade".

\section{PRODUZINDO NOVOS SIGNIFICADOS E AÇÕES}

Assim, à medida que os membros do GEEU expressavam suas visões de mundo, no espaço do muro, estabelecendo laços mais fortes de amizade e dotando aquele determinado espaço de valores, transformaram-no em um lugar impregnado de significados e fortificado por uma rede de relações. Com isso, é possível pensar esse ambiente artifícializado como um lugar singular onde podem ser vividos sentimentos e relações imprescindíveis ao cotidiano humano.

Como afirma Magnani (op. cit.:13), nas dimensões do lazer e da sociabilidade, "tanto as formas convencionais como aquelas mais inusitadas atestam a vitalidade das práticas urbanas". As genuínas experiências urbanas, com todos os seus problemas, ainda existem e, 
conforme o referido autor, elas se diversificaram, : assumindo novas modalidades, adaptando-se a novas : circunstâncias e estabelecendo outros diálogos.

Não se pode, portanto, negar a possibilidade da : manifestação do lúdico, do prazer (ainda que atrelado : ao dever) e da sensibilidade na vivência de atividades : em ambientes artificializados, particularmente em . muros artificiais de escalada. Estes, por sua vez, são : impregnados de experiências cotidianas das pessoas, : apontando uma nova forma de experimentação.

Remetendo-nos aos escritos de Foucault (apud Ortega, : 2000), é possível perceber como as diversas formas : de vida em comum não se esgotam, necessariamente, : em uma instituição. Vive-se uma sociedade na qual " as relações permitidas são extremamente reduzidas : e simplificadas. Contudo, os processos de: diferenciação e de liberação, característicos da : sociedade contemporânea, tornam possível o : questionamento e a relativização da validade e do : alcance de vínculos orgânicos que garantam a coesão : das sociedades tradicionais (religião, família, trabalho). " Esse processo deve ser aceito como oportunidade de nova configuração de seus relacionamentos, criando : e experimentando diferentes formas de existência e : de comunidade.

Na mesma linha de Arendt, Foucault propõe a : animação da vontade de agir e de experimentar, : conduzindo os seres humanos a sua condição de : homo ludens, fazendo um apelo à participação nessa nova comunidade. $\mathrm{O}$ único argumento utilizado, nesse : apelo, é a fascinação que o agir produz como início : de algo novo. Os laços de amizade, formados e : fortalecidos no muro do GEEU parecem caminhar : nessa direção, manifestando uma sociabilidade vivida : além dos padrões familiares, sob uma singular forma : de experimentação de pensamentos e ações.

\section{REFERÊNCIAS BIBLIOGRÁFICAS}

ATTARIAN, Aram. Artificial rock climbing walls - : innovative adventure environments. Journal of: Physical Education, Recreation and Dance, v.60, no7,1989.

ATTARIAN, Aram. Rock climbing in the great indoors.
Journal Parks and Recreation, v.22,

december,

1987. FEATHERSTONE, Mike. O curso da vida: corpo,

cultura e imagens do processo de envelhecimento.

In: DEBERT, Guita (org.). Textos Didáticos. Campinas: IFCH, UNICAMP, 2a ed., nol3, janeiro, 1998. FESKO, Charli. Social Climbers. Athletic

Business.

January, 1992. Folha de São Paulo, Folha

Esporte, 27 de dezembro

de 1998, p.3-4. GEERTZ, Clifford. A

interpretação das culturas. Rio

de Janeiro: Guanabara Koogan, 1989.

HARVEY, David. Condição Pós-moderna. São Paulo: Edições Loyola, 1992. HYDER, Martha A.

Have your students climbing the walls - the growth of indoor climbing. JOPERD The Journal of Physical Education, Recreation \& Dance, v. 70, no. 9, novembro ./dezembro, 1999, p.32-39. HUMBERSTONE, Barbara. Bringing

outdoor education

into the Physical Education agenda: gender identities and social change. Quest: The Journal of the National Association for Physical Education

in Higher Education. no 47, 1995, p. 144-157. MAFFESOLI, Michel. No fundo das aparências. Petrópolis, RJ: Vozes, 1996. MAGNANI,

José. G. C. Transformações na cultura urbana das grandes metrópoles. In: MOREIRA, Alberto S. (org.). Sociedade Global: Cultura e religião. 2a ed., Petrópolis: Vozes, 1999. ORTEGA, Francisco. Para uma política da amizade-. Arendt, Derrida, Foucault. Rio de Janeiro: Relume Dumará, 2000. PARLEBAS, Pierre.

Elementos de sociologia dei deporte. Málaga: Junta de Andalucia - Universidade Internacional Deportiva de Andalucia, 1988. Publicação do SESC - São Paulo, no.10, v.2 no. 3, abril de 1999, p.12-19. REIGOTA, Marcos. O que é educação ambiental.

$2^{a}$ ed., São Paulo: Brasiliense, 1998. Revista da Folha. 17 de outubro de 1999, p.6-11. SANTOS, Milton. A natureza do espaço - técnica e tempo, razão e emoção. São Paulo: Hucitec, 1997. TUAN, Yi-Fu. Espaço e lugar - a perspectiva da experiência. São Paulo: Dipel, 1983. 


\section{NOTAS}

${ }^{1}$. As reflexões aqui apresentadas fazem parte de uma : pesquisa de mestrado, tendo como ponto de partida para : análise o Grupo de Escalada Esportiva da Unicamp (GEEU). " São apontados alguns discursos de escaladores (integrantes : do referido grupo), os quais foram obtidos por meio de : entrevistas.

${ }^{2}$. Outro estudo, partindo dessa mesma idéia, pode ser : lido na Revista JOPERD, no artigo de Hyder (nov./dez. de " 1999).

Destacamos, também, que, desde agosto de 1999, um " projeto de extensão à comunidade, em iniciação à escalada : esportiva, vem sendo desenvolvido na FEF, ministrado " pelos próprios membros do GEEU e sob a coordenação " do Prof. Dr. Júlio Gavião, docente da referida instituição). " 3. SESC - São Paulo, abril de 1999.

4. A palavra alpinismo apesar de, muitas vezes, ser utilizada " para designar, genericamente, o ato de escalar, tem sua " origem em escaladas nos Alpes. No dicionário Aurélio : pode-se verificar que montanhismo é sinônimo de : alpinismo. O montanhismo representa a prática de : atividades em regiões montanhosas, tais como caminhadas, " acampamentos em finais de semana, até caminhadas de : ascensão, escaladas em rocha, gelo e outras. De acordo : com Tomas Griddi Papp, coordenador do Pró-Esportiva " (Programa Brasileiro de Desenvolvimento da Escalada " Esportiva) do Clube Alpino Paulista, existem nove tipos " de escalada: escalada em livre; escalada esportiva; escalada " de competição; escalada esportiva em estruturas artificiais; " progressão artificial em rocha; big wall; escalada alpina; * alta montanha e cascatas de gelo (Folha Esporte - Folha : de São Paulo, 27 de dezembro de 1998).

5 . Maffesoli (ibidem:233) refere-se ao fato de as ligações sociais estarem, em todos os momentos, sendo fortalecidas por uma espécie de comunhão com a natureza. Como : exemplo, o autor utiliza as populosas ruas de Tóquio, : onde tudo é artifício e a agitação é dominante, no entanto, ainda assim, é possível se encontrar em um cruzamento de rua qualquer, em uma esquina, "um pequeno altar : dedicado aos espiritos tutelares, servindo de anamnese : dos ancestrais fundadores e das forças da natureza". " Vários outros exemplos poderiam ser utilizados, como os " cultos a Iemanjá nas praias cariocas. Nessa direção, tratando " da questão da "naturalização da cultura", Maffesoli se " propõe a tratar da "ecologização do mundo social". " Conceito utilizado para mostrar que a natureza não é mais considerada como um mero objeto, susceptível de explorações, mas capaz de se inscrever progressivamente, em um processo de parceria, não podendo mais ser estranha ao debate social e sendo, provavelmente, uma modulação do hedonismo da contemporaneidade: usufruir aqui e agora os prazeres oferecidos pela terra. ${ }^{6}$. Esse autor relata que o gosto pelo natural "pode se estender da utilização da madeira, em suas diversas formas, às armações de concreto bruto que, no seio de sua artificialidade, remetem à ligação com a grande deusa terra. A moda dos produtos naturais, sua venda mais ou menos ideologizada vão também nesse sentido. A roupa não escapa a esta determinação, a tecelagem, a lã, o couro, etc. estão aí para lembrar que a pele social deve a pele natural (...). Em todos os casos, assiste-se à produção de um discurso específico que integrou a evidência da naturalidade das coisas". ${ }^{7}$. Para tratar de questões referentes às transformações na cultura urbana de grandes metrópoles, Magnani reporta-se à Conferência das Nações Unidas sobre Assentamentos Humanos Habitat 2 (realizada na Turquia, em 1996), destacando, conforme relatórios desse evento, a cidade de São Paulo como um exemplo de anti-cidade. Por contrapartida, para dar "bons exemplos de práticas urbanas", o autor (ainda com base na citada conferência e em outras reportagens), procura apontar a mudança de enfoque sobre as grandes cidades. ${ }^{8}$. Concretizando o sonho de nevar em São Paulo, aconteceu em junho de 2000, no Ginásio do Pacaembu, um "Encontro Mundial de Snowboarding". O local esteve completamente lotado por praticantes e curiosos desse esporte, tendo em vista que foi o maior evento do gênero no Brasil. A neve artificial foi colocada sobre uma rampa, possibilitando deslizes e saltos dos atletas. ${ }^{9}$. Meio ambiente está sendo, aqui, entendido como "um lugar determinado e/ou percebido onde estão em relações dinâmicas e em constante interação os aspectos naturais e sociais. Essas relações acarretam processos de criação cultural e tecnológica e processos históricos e políticos de transformação da natureza e da sociedade" (Reigota, 1998:21)

\section{ENDEREÇO PARA CONTATO}

Avenida 8,1837 apto: 74 Edifício Jardim Claret

CEP: $13503-210$

Rio Claro (SP) - Tel: (19) 5234372

E-mail: alcyane@claretianas.com.br 